\title{
Relation between electroconvulsive therapy, cognitive side effects, neuron specific enolase, and protein S-100
}

\author{
M W Agelink, J Andrich, T Postert, U Würzinger, T Zeit, P Klotz, H Przuntek
}

\begin{abstract}
Objective-To investigate whether electroconvulsive therapy (ECT) induces brain tissue damage expressed as an increase in neuron specific enolase and protein S-100. Methods-A total of 179 serial measurements of S-100 and NSE serum concentrations were performed on 14 patients during the course of a bilaterally stimulated ECT series. Cognitive performance was assessed by psychometric testing carried out on the day before the start of ECT as well as on the days after the third, sixth, and last ECT. Pre-ECT and post-ECT concentrations of NSE and S-100 were compared by non-parametric tests.

Results-On average, 9.5 (SD 2.9) (range 3-12) ECTs were applied; 13 of 14 patients received at least six ECTs. The average duration of convulsion (computed for all ECTs) was 29.0 (SD 10.5) seconds. At no point during the ECT series was there a significant increase in the average NSE or S-100 concentrations compared with the baseline investigation before the start of the ECT series. The maximal measured post-ECT values of NSE and S-100 were $26.6 \mathrm{ng} / \mathrm{ml}$ and $0.46 \mathrm{ng} / \mathrm{ml}$, respectively. The cumulative energy doses applied, seizure durations, and ECT induced changes in cognitive performance scores were never significantly correlated with the NSE or S-100 serum concentrations. Conclusion-This pattern of findings suggests that a modern ECT, fulfilling current quality standards, induces no brain tissue damage detectable by changes in NSE or protein S-100.
\end{abstract}

(F Neurol Neurosurg Psychiatry 2001;71:394-396)

Keywords: electroconvulsive therapy; epilepsy; neuronspecific enolase; protein S-100

The application of electroconvulsive therapy (ECT) has always been a controversially discussed topic both in the lay press and among clinical experts. About a third of treated patients have usually reversible cognitive problems after ECT; particularly worthy of mention is retrograde amnesia for autobiographical and impersonal material. Right unilateral ECT results in less severe short term and long term cognitive effects compared with bilateral ECT, but it is less efficacious. ${ }^{1}$ Critics of ECT have postulated an association between the functional, cognitive disorders occurring after ECT, and cerebral structural damage, although all attempts until now have failed to confirm any ECT induced structural brain tissue damage, either in postmortem studies or by using various neuroradiological examination procedures. $^{23}$

To provide evidence for an ECT induced, diffuse, and small microstructural brain alteration (associated with acute neural or glial damage, but which may escape detection by post-ECT imaging procedures), the measurement of protein S-100 and neuron specific enolase (NSE) might prove to be useful. Neuron specific enolase is a dimeric glycolytic enzyme which is found in the cytosol of various neurons in the CNS. Protein S-100 is an acidic calcium binding protein that is present in the cytosol of astroglial cells. Both proteins seem to be more verifiable after acute CNS damage than they are during neurodegenerative disease; they are considered to represent sensitive, biochemical markers for brain damage after generalised seizures, trauma, hypoxia, or ischaemic stroke. ${ }^{4-6}$ An association between concentrations of NSE in serum and cognitive disorders after operative interventions was recently confirmed.?

Our prospective study, whereby a total of 179 serial measurements of S-100 and NSE were performed from 14 patients during the course of a bilateral ECT series, was designed to answer the following questions: $(a)$ is there an increase in plasma NSE, or S-100 protein, or both after bilateral ECT? (b) Does the applied energy dose or the duration of convulsions influence the concentration of either marker? $(c)$ are there any associations between concentrations of NSE, S-100, or both and the cognitive effects of ECT?

\section{Methods}

The study was approved by our local ethics committee. The patients (five women, nine men) were on average 54.0 years old (SD 17.6, range 22-79); the diagnoses (DSM-III-R) were a therapy resistant major depression $(n=8)$ or a schizodepressive psychosis $(n=6)$. Apart from their psychiatric state, patients were otherwise 
in a healthy condition and all were receiving ECT for the first time (except for one patient who had received 12 unilateral ECTs 8 months previously).

Due to the severity of depressive symptoms, six patients occasionally received lorazepam (maximum dose $3 \mathrm{mg} /$ day); other psychopharmaceutical drugs were not applied during the ECT series. For all patients, propofol was used as the anaesthetic, and norcurone and succinylcholine served as muscle relaxants. The ECT was performed at 2 day intervals with bifrontotemporal stimulation ${ }^{8}$ using the Thymatron ${ }^{\mathrm{TM}}$ DG apparatus; the stimulus (1 ms brief pulse) intensity used in all cases was about $50 \%$ above the previously determined convulsion threshold. During ECT, the EEGs and ECGs were continuously recorded. Seizure duration and quality were measured using a visual rating of electroencephalographic regularity and postictal suppression.

Three psychometric tests were carried out on the day before the start of ECT as well as on the days after the third, sixth and last ECT: (a) the information memory concentration test (IMC), a subtest of the dementia scales from Blessed et al (1968) which tests orientation, short term and long term memory, and concentration $^{9} ;(b)$ the digit span test for examining short term memory ${ }^{10}$; and $(c)$ version A-E of the Syndrom Kurztest (SKT) for recording memory and attention disorders. ${ }^{11}$ The total point scores achieved in each test were used for statistical evaluations. The physician carrying out the psychometry was blinded both to the ECT indices as well as the laboratory results.

Blood samples for determining NSE and S-100 were taken on the day before the ECT series was started, 6, 24, and 48 hours after the first to third ECT, and 24 hours after the fourth, fifth, sixth, and last ECT. Samples were stored at $-20^{\circ} \mathrm{C}$ until analysis. The NSE and S-100 were measured according to procedures previously published by our group. ${ }^{4}$

\section{STATISTICS}

For comparing NSE or S-100 concentrations between pre-ECT and post-ECT measurements, the paired Wilcoxon test was used. Individual values were considered to be abnormal when they differed from the mean of the patients' pre-ECT values by more than 3.0 SD. Correlations between variables were tested using the Spearman correlation coefficient.

\section{Results}

On average, 9.5 (SD 2.9) ECTs were applied (range 3-12); 13 of 14 patients received at least six ECTs. The average charge applied increased from an initial $171 \mathrm{mC}$ (SD 55, range $100-252 \mathrm{mC}$ ) to $239 \mathrm{mC}$ (SD 92, range 128$378 \mathrm{mC})$ at the last ECT $(\mathrm{p}<0.01)$. The average length of convulsion (computed for all ECTs) was 29.0 (SD 10.5) seconds (range 19-58 s).

There were no significant correlations between the cumulative energy doses applied or the duration of convulsions, and the NSE or S-100 concentrations. Figure 1 shows the mean values (SD) of NSE and S-100 at all
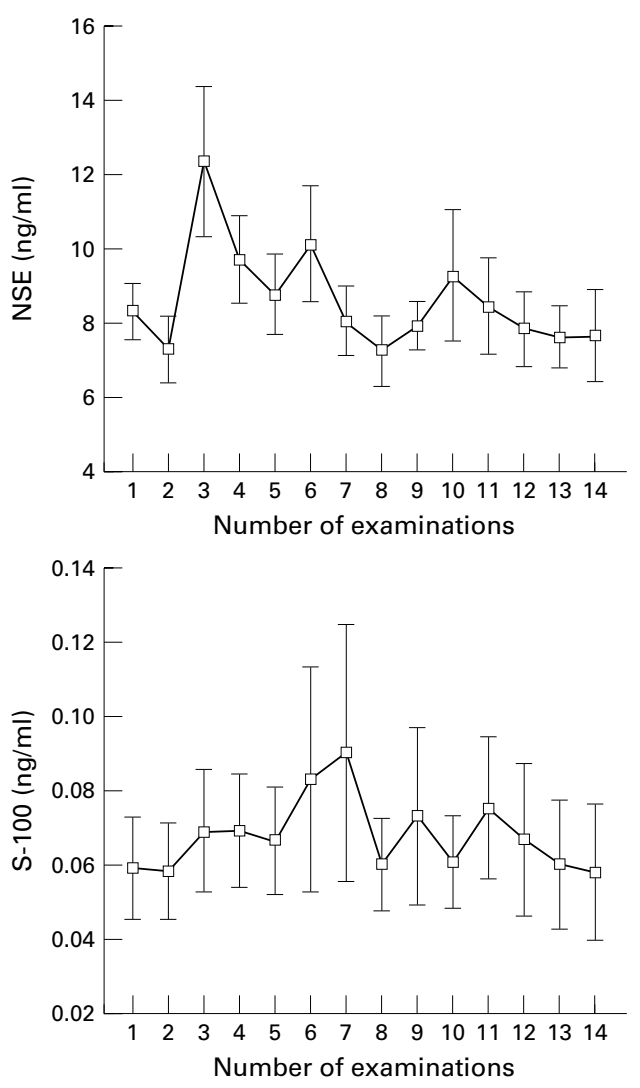

Figure 1 Mean (SD) values of (A) NSE and (B) S-100 serum concentrations before the start of ECT and during the follow up. Fourteen patients received at least three ECTs (examinations $1-10$; see methods) 13 patients at least six (examinations 11-13), and 10 patients more than six ECTs (examination 14).

measuring points. During the ECT series, the average NSE concentrations measured 24 hours after ECT (that is, at examinations 3, 6, 9, and 11-14) showed a trend to decrease (fig 1 A). At no point during the ECT series was there a significant increase in mean protein concentrations compared with the baseline investigation before the start of the ECT series. The maximum post-ECT NSE and S-100 values were $26.6 \mathrm{ng} / \mathrm{ml}$ and $0.46 \mathrm{ng} / \mathrm{ml}$, respectively. Our definition for an abnormally raised NSE or S-100 (mean values before onset of the ECT series+3 SD) resulted in upper thresholds of $26.1 \mathrm{ng} / \mathrm{ml}$ for NSE and $0.28 \mathrm{ng} / \mathrm{ml}$ for S-100. An abnormal increase in NSE was only found transiently (24 hours after the third or fourth ECT), with two patients being affected (a 79 year old woman with major depression and a 45 year old man with a schizodepressive psychosis). With the schizodepressive patient, the threshold was exceeded after the third ECT along with the S-100 threshold value, and with both patients an improvement in performance was seen with all three psychometric tests over the course of the ECT series.

Table 1 shows the means (SD) of the total point scores achieved for every psychometric test. There was no significant correlation between NSE or S-100 concentrations, and the performance scores in any of the tests. Interestingly, patients who showed higher S-100 concentrations after the last ECT compared 
Table 1 Mean total score (SD) of the psychometric test results

\begin{tabular}{lcccc}
\hline Cognitive tests & Before ECT & After 3 ECTs & After 6 ECTs & \multirow{2}{*}{ After the last ECT } \\
\hline ICM & $35.5(2.6)$ & $35.2(3.2)$ & $35.3(3.0)$ & $35.9(2.2)$ \\
Digit span & $9.5(1.4)$ & $10.3(2.2)$ & $10.0(2.2)$ & $11.1(2.3)$ \\
SKT & $7.2(5.1)$ & $5.9(4.6)^{\star}$ & $6.7(4.6)$ & $6.5(4.3)$ \\
\hline
\end{tabular}

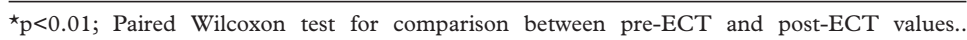
ICM=Information memory concentration test; SKT=Syndrom Kurztest.

with the baseline study $(n=4)$ showed an improvement in cognitive test results for all three tests compared with patients showing no increase in S-100 (measured as the individual differences in the pre-ECT and post-ECT total point scores), whereas in the ICM test these differences were significant despite the small group size (Mann-Whitney test, $\mathrm{p}<0.05$ ). In addition, among patients with higher NSE values compared with baseline after the last ECT $(n=4)$ we found a trend for a better performance in the ICM test compared with patients with lower NSE values compared with baseline (Mann-Whitney test, $\mathrm{p}<0.08$ ).

\section{Discussion}

A significant increase in serum NSE concentration has been demonstrated after generalised epileptic seizures. ${ }^{413}$ In our study there was never a significant increase in average NSE or S-100 concentrations at any time during the course of an ECT induced series of generalised convulsions. All measured NSE values were lower than $30 \mathrm{ng} / \mathrm{ml}$, and therefore lower than the pathological threshold reported in the literature. ${ }^{14}$ This pattern of findings suggests that (1) a postictal increase in NSE is a sign of neuronal damage, which is apparently not due to the epileptic seizures themselves, but is caused rather by the simultaneously occurring hypoxia, or indeed other mechanisms; and (2) a modern ECT that fulfils current quality standards (guarantees of seizure monitoring, muscle relaxation, hyperoxygenation, and ventilation wherever appropriate) induces no detectable brain tissue damage measured as changes in NSE or protein S-100. This is consistent with our finding that neither the energy dose applied nor the seizure duration affect S-100 or NSE concentrations.

Our results correspond with those of a recently published study in which no increase in protein S-100 concentration in CSF was found among depressive patients $(n=9)$ after application of six unilateral ECTs. ${ }^{15}$ To our knowledge, the only prospective case study which has ever measured NSE concentrations during the course of an ECT series was also limited to a unilateral ECT; this showed a trend towards a decrease in NSE concentrations after completion of an ECT series among five of seven patients compared with the initial pre-ECT examination. ${ }^{16}$ The small decrease in average NSE-release during a bilateral ECT series, as shown in our study, is a similar finding and might be explained by an increasing drainage of neuronal NSE stores, or by an accelerated enzymatic breakdown of NSE.

On the basis of animal experiments, some researchers have postulated an association between a seizure induced astrocyte activation followed by a release of neurotropic factors (including NSE), and synaptic remodelling occurring as a result of the seizure attack. ${ }^{17}$ If these findings are applied to our study, the question might be asked whether an ECT induced release of NSE promotes neural plasticity in isolated cases, and whether it even plays a part in the antidepressive or cognitive effects of ECT. Support for this thesis is provided by our finding that patients with higher post-ECT values of NSE and S-100 (compared with the pretreatment values) showed the best cognitive test performances. Although we cannot exclude the possibility that this is merely a coincidental finding due to the small sample size, this interesting result should be the subject of future investigations on the cognitive effects of ECT.

1 Sackeim HA, Prudic J, Devanand DP, et al. A prospective, randomised, double-blind comparison of bilateral and right ateral electroconvulsive therapy at different stimulus intensities. Arch Gen Psychiatry 2000;57:425-34.

2 Coffey CE, Weiner RD, Djang WT, et al. Brain anatomic effects of electroconvulsive therapy: a prospective magnetic effects of electroconvulsive therapy: a prospective magnetic
resonance imaging study. Arch Gen Psychiatry 1991;48: 1013-21.

3 Devanand DP, Dwork AJ, Hutchinson ER, et al. Does ECT alter brain structure. Am f Psychiatry 1994;151:957-70

4 Büttner $\mathrm{T}$, Lack B, Jäger $\mathrm{M}$, et al. Serum levels of neuron-specific enolase and S-100 protein after single tonic-clonic seizures. $\mathcal{F}$ Neurology 1999;246:459-61.

5 Ingebrigtsen $\mathrm{T}$, Romner B, Kongstad P, et al. Increased serum concentration of protein S-100 after minor head injury: a biochemical serum marker with prognostic value? injury: a biochemical serum marker with progn

6 Persson L, Hardemark HG, Gustafsson J, et al. S-100 protein and neuron-specific enolase in cerebrospinal fluid and serum: markers of cell damage in human nervous system. Stroke 1987;18:911-18.

7 Rasmussen LS, Christiansen M, Hansen PB, et al. Do blood levels of neuron specific enolase and S100 protein reflect cognitive dysfunction after coronary artery bypass? Acta Anaesthesiol Scand 1999;43:495-500.

8 Weiner RD. Electroconvulsive therapy. In: Kaplan HI, Sadock BJ, eds. Comprehensive textbook of psychiatry. Baltimore, Williams and Wilkins, 1989:1670-8.

9 Blessed G, Tomlinson BE, Roth $M$. The association between quantitative measures of dementia and of senile change in the cerebral grey matter of elderly subjects. $\mathrm{Br} \mathcal{F}$ Psychiatry 1968;114:797-811.

10 Wechsler D. A standardized memory scale for clinical use. $f$ Psychol 1945;19:87-95.

$11 \mathrm{Kim}$ YS, Overall JE. Factor structure and scoring of the SKT test battery. F Clin Psychology 1991;49:61-71.

12 Büttner T, Weyers S, Postert T, et al. S-100 protein: serum marker of focal brain damage after ischaemic territorial MCA infarction. Stroke 1997;28:1961-5.

13 Rabinowicz AL, Correale JD, Boutros RB, et al. Neuronspecific enolase is increased after single seizures during inpatient video/EEG monitoring. Epilepsia 1996;37:122-5.

14 Prange HW. Pathophysiologie, Therapie und Prognose des hypoxisch-ischämischen Hirnschadens. Z Kardiol 1994;83: $127-34$.

15 Zachrisson OC, Balldin J, Ekman R, et al. No evident neuronal damage after electroconvulsive therapy. Psychiatry Res 2000;96:157-65.

16 Berrouschot J, Rolle K, Kühn HJ, et al. Serum neuronspecific enolase levels do not increase after electroconvulsive therapy. F Neurol Sci 1997;150:173-6.

17 Kragh J, Bolwig TG, Woldby DPD, et al. Electroconvulsive shock and lidocaine-induced seizures in the rat activate astrocytes as measured by glial fibrillary acidic protein. Biol Psychiatry 1993;33:794-800. 